\title{
Study and Practice of the Cultivation of Mathematics Teaching Design Ability for Normal College Students
}

\author{
Zhenhui Xu \\ Applied Technology College, Southwest University of Science and Technology, Mianyang 621010, China \\ E-mail: xuzhenhui@swust.edu.cn
}

Hanlin Chen

School of Science, Southwest University of Science and Technology, Mianyang 621010, China

E-mail:chenhanlin@swust.edu.cn

The research is financed by the Education Teaching Reform Fund of 2006 of Mianyang Normal University (No. JY2006013). (Sponsoring information)

\begin{abstract}
With the development of the course reform of elementary education, the requirements that the classroom teaching should fully embody the new concept of education and inspire students to actively participate in classroom teaching are higher and higher, so high school teachers should have stronger teaching design ability. To make normal college students to be competent for the mathematics teachers of high school after they graduate, the cultivation of their classroom teaching design ability should be strengthened. The concrete strategies include following aspects, i.e. strengthening normal college students' learning of the learning theory and the teaching theory and establishing correct teaching concept, confirming the guiding ideas of mathematics classroom teaching deign under new course environment, confirming the contents of the mathematics classroom teaching design, apperceiving the mathematics classroom teaching design by various channels and modes, and instructing normal college students to study and discuss materials intensively, attempt design and practice, and summarize experiences.
\end{abstract}

Keywords: Normal college students, Mathematics classroom, Teaching design, Practice, Effects

\section{Backgrounds and meanings}

Under new course environment, teacher' role has changed from past knowledge initiator, supervisor and luminary into promoter, guide and cooperator for students' learning (Zhong, 2001). The teaching process is the interactive process of the communication and mutual development between teachers and students, and teaching becomes into the creation process of teachers and students full of personality, and both teachers' teaching methods and students' learning methods will change. So teachers should create various teaching situations to inspire students' learning passion and motive, lead them to actively participate in the learning, and continually propose questions and explore strategies for solving problems, and make students obtain active and deep experiences accruing to the teaching contents. The teaching mode should be multiform, and the teaching should be implemented creatively, which can design proper learning activities for students and make the classroom full of passion. These series of changes require teachers must seriously design the teaching of mathematics classroom. Therefore, to be competent for the teaching of mathematics in high schools and be eligible mathematic teachers after graduating, normal college students must enhance their teaching design ability of mathematics classroom.

The so-called mathematics classroom teaching design is to use systematic method to organize various teaching materials organically under the guidance of teaching theory and learning theory in the lesson preparation, and plan various associated parts, and confirm the analysis and research methods, and propose the approaches to solve problems, and analyze the anticipated result (Zhou, 2002). That is to say, to achieve the teaching target of mathematics classroom, plan how to teach, what to teach, and what effect that the teaching should achieve. For teachers, the mathematics room teaching design is a creative work.

\section{Strategies and methods to cultivate college students' ability of mathematics classroom design}

\subsection{Cultivating students to confirm the contents of mathematics classroom teaching design}

How the mathematics teaching activity is implemented is to design the activity of teaching and learning, and it is the core part of teaching design, and it includes following aspects.

(1) The mathematics teaching content should present the design of the process. The contents include the design of teaching target, the design of new lesson lead, the design of explaining emphases and difficulties, the design of 
experiment, demonstration and modern teaching media assistant cooperation, and the design of blackboard writing.

(2) The design to instruct learning activity. And the contents include the design of instructing reading materials, the design of illuminating thinking and inspiring asking, the design of organizing students to exercise, and the design of instructing summarization and induction, and the design of instructing transfer and utilization.

(3) The design of anticipating the feedback information and adopting teaching countermeasures in time

These designs are integrated in concrete teaching activities, and they are arranged according to the time of course, and the integrated optimization in the teaching and learning is embodied in the ordered arrangement of many factors such as teachers, students, teaching materials and medias, that is the difficult point in the classroom teaching design.

\subsection{Strengthening college students' learning of the teaching theory and the learning theory and establishing correct teaching conception}

In the teaching, the teaching principles of high school mathematics should be explained combining with practical examples to lead normal college students to deeply know and discuss the teaching method, teaching measure and teaching strategy of mathematics, seriously analyze the characters, advantages and deficiencies of various teaching methods, study and grasp the high school mathematics concepts, mathematics methods and extensive application. At the same time, normal college students should be leaded to discuss the formation, development and perfection process, general rule of high school mathematics cogitation structure, and the structure and character of mathematics lesson, and analyze the main factors in the teaching process of mathematics, and make normal college students to confirm the essential, characters and type of mathematics learning, and grasp the basic methods and strategies of mathematics teaching and the essential differences between traditional teaching method and mode with present teaching method and mode advocated in new lesson. Normal college students should fully know the effective behaviors of teachers' high school mathematics teaching and the effective behaviors of students' learning, and establish correct teaching concept, i.e. taking teachers as the dominant part, taking students as the main body, taking the development as the major idea, and mainly cultivating students' innovational spirit and practice ability.

\subsection{Confirming the guidance ideas of classroom teaching design under new course environment}

(1) Fully embodying the basic "students' development-oriented" concept in new mathematics course (Xu, 2003).

The course reform of elementary education should takes "students' development" as the basic course concept, and "students' development" means the development of all students, i.e. the comprehensive and harmonious development, the durative development for life, the lively development, and the development of personality and specialty. Therefore, the classroom teaching design should fully embody the function of main body of students, and create proper teaching situation and conditions for the development of each student, inspire students' strong learning needs and interest, and lead them to participate and explore actively, i.e. the exploring and discussion activities in the question situation design and teaching process should orientate to each student with difference, and pay attention to each student, and let all students participate and experience them as possibly, and make students to understand, grasp and utilize the knowledge in independent activities, and at the same time, the classroom teaching design should not only emphasize the teaching of elemental knowledge and the training of basic skills, and develop students' wisdoms and abilities, but promote the formation of their active emotions and attitude, and correct value concept, fully respect students' personality, and build a democratic, equal and harmonious teaching atmosphere to make students develop comprehensively.

(2) Effectively integrating three factors including teacher, student and teaching material, reasonably grasping the classroom structure and embodying the most optimized idea.

The design of mathematics classroom teaching should treat the mathematics activities by systematic eye and dynamic concept, balance the position of teaching and learning, and translate the teaching principle into the plan of teaching activity. The famous psychologies of US, Robert Mills Gagne, proposed a catchword of "designing teaching for learning". He thought that the teaching was that people created environment elaborately, inspired, supported and drove the happening of interior process of learning, and achieved the learning result by the function of exterior conditions. When designing the mathematics classroom teaching, teachers should take students' activity as the principle part of behaviors, start from students' needs, seriously analyze the development level, cognition mode and existing living experience, and knowledge experience of learning, and deeply dig the ideas and contents of teaching materials, and reasonably organize the teaching contents. Teachers should confirm and embody the target of classroom teaching, try to create the teaching situation for students' thinking, offer proper learning guidance and condition support, organize students to experience the course of mathematic exploring to the most extent, offer wide thinking space for students, and realize the learning mode that students actively participate and explore, suppose, and communicate, and orderly develop the thinking activities including finding problems, discussing problems, communicating and solving problems to achieve the most optimized effect of teaching. Concretely speaking, the mathematics classroom teaching design should arrange the teaching process systematically and elaborately from five aspects. First, the time of one lesson should include a group of "module" such as introduction, discussion, conclusion, exercise, confirmation, or transfer. 
Second, the organization order of the teaching content should give priority to students' psychological development order, and give attention to the logic orders of knowledge. Third, when selecting teaching method, teaching media and confirming teaching strategy, the rationality and the optimized combination should be embodied. Fourth, the teaching organization form should mainly consider the proper interaction among teachers and students, strengthen the communication power in classroom, and properly convert the interactive mode according to the practice of classroom. Fifth, the development of classroom teaching activity should follow the cognitive rule of learning course including inspiring motive and interest, apprising target, memorizing relative old knowledge, presenting new tasks, instructing the understanding, and offering the opportunity for each student to attempt exercise and experience results, elaborately arrange the homework to further confirm and transfer. And it should make the mathematics classroom full of vital forces and energies, and make students to realize the essence of mathematic thinking, exercise the mathematical thinking, grasp the thinking method of mathematics, know the essence of mathematics, and comprehensively and harmonious develop the mathematics teaching in the mathematical teaching process.

(3) Opening out the thinking process, and cultivating students' innovational spirit and practice ability.

The classroom teaching should intentionally design the long-term target of innovational education, for example, the setting of "question situation" should be beneficial to inspire students to actively consider, suppose boldly, actively explore and dig new questions, promote deeper thinking, fully dig students' interior potentials, and develop students' thinking innovation. In the exploring process of question, students should have deficient space and opportunities of independent consideration to independently analyze, study, and solve problems, and students should be cultivated to have the ability to obtain new knowledge, and really "seek experiences by participation and develop by innovation".

\subsection{Apperceiving the mathematics classroom teaching design by various channels and modes}

(1) Teachers of the teaching method should demonstrate the classroom teaching of mathematics in high schools.

(2) Organize normal college students to practice of classroom teaching in local high schools, and invite famous teachers of high school to explain demonstration lessons.

(3) Organize normal college students to look on good teaching videos, and read teaching cases.

Normal college students should really perceive the mathematics classroom teaching of high school, understand the classroom teaching design, and analyze, discuss, and evaluate these various classroom teachings. For example, the setting of question situation should be close to life and practice, and induce the students to put forward questions, and with the development of teaching process, a continual question process can be formed, i.e. a question chain which can inspire students to think will be formed, and it can create a process full of observation, association, abstraction, generalization and mathematization. The actively mode design of students exploring and discussion and communication should be proper, and the teachers should instruct students' consideration, and limit students' thinking range properly. Aiming at the requirements and targets of various parts in the mathematics classroom teaching, normal college students should express their own opinions and discuss them together to promote them to translate the "academic formation" of mathematic knowledge into the "educational formation" (Zhang, 2005), and really know and experience the essential meaning of the classroom teaching design.

2.5 Instructing normal college students to study and discuss materials intensively, attempt design and practice, and summarize experiences

(1) Normal college students should analyze the teaching materials (the angle of editor, the angle of students, and the angle of teachers) from different angles, and they should be instructed to analyze the status, function,, knowledge structure, and character of teaching materials according to different contents.

(2) Instruct normal college students to confirm the teaching requirements, emphases and key points, elaborately select teaching contents with characters such as foundation, exemplification, structure and representative character.

(3) Instruct normal college students to organize materials, reasonably confirm the teaching strategies, and correctly select the teaching method according to the "order" of the teaching materials and the "order" cognized by students.

(4) After seriously analyzing and deeply studying the teaching materials, normal college students should be organized to attempt to design various parts, and then communicate and discuss, and fully declare themselves, and improve comparing with the rules.

(5) Organize students to teach in the small classroom, and then discuss and evaluate, and improve for measure.

For example, in the lesson of "the monotonicity of the function", multiple modes can be designed in the lead part through discussion and study.

(1) The mode of direct lead. At the beginning of the lesson, bring forth the teaching targets. (a) Understand the monotonicity of the function and the meaning of the monotony interval, and understand the proving method of the function monotonicity. (b) Judge the monotonicity of the function according to the image and definition, and prove the 
monotonicity of the function in the interval. (c) Utilize the monotonicity of the function to solve the value domain of the function. This method can point out the learning contents and keys, and strengthen the intention of learning, and enhance the attention of learning.

(2) The mode of review lead. First, show the image of the quadratic function $y=x^{2}$ which has been already learned, and combining with the image, lead students to review the characters of the function, i.e. the image of the function is ascending in the right side of the axis of $y$, and the image of the function is descending in the left side of the axis of $y$, and then introduce the monotonicity of the function. This method uses the review of old knowledge to naturally lead the new lesson, which can make for the association between new knowledge and old knowledge, and improve the understanding of new knowledge.

(3) The mode of question lead. Teacher gives following question first and let students to discuss at the beginning of new lesson.

For the function of $y=\frac{1}{2} x^{2}$, (a) if $a 、 b \in[0,2]$, and $a<b$, can $f(a)$ and $f(b)$ be compared? (b) if $a, b \in[-3,0]$, and $a<b$, can $f(a)$ and $f(b)$ be compared? (c) if $a, b \in[-3,2]$, and $a<b$, can $f(a)$ and $f(b)$ be compared?

This method can catch the inconstancy of the question to lead students, which can arouse the cognitive conflict, expose the thinking obstacle, and successfully create the situation of question.

(4) The mode of observation lead. First, students should observe the functions in the corresponding intervals, and point out their main differences in character (the images of these two groups of function are offered by the overhead projector).

The first group of function:
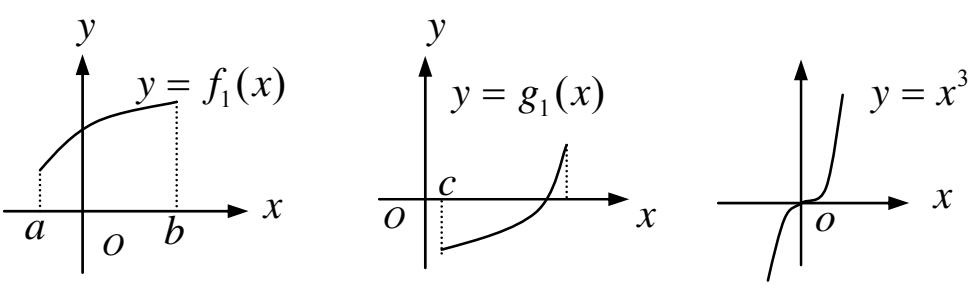

The second group of function:
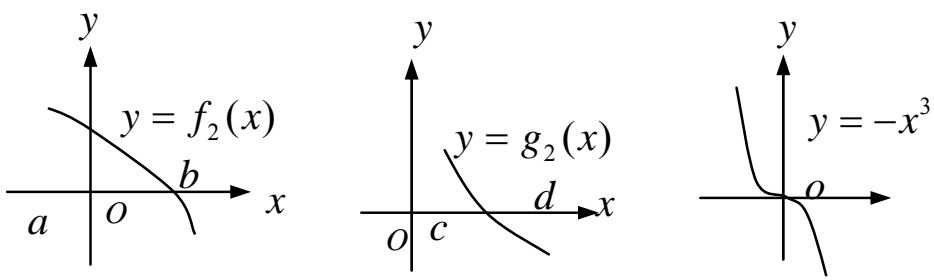

After various parts are designed, the teaching project of one lesson can form, and then organize normal college students to teach in small classroom, and discuss and improve the concrete problems in the practice teaching. Though repetitive discussion, research, improvement, and practice teaching, normal college students can more deeply know and understand the teaching and learning in the high school mathematics, so their ability of the classroom teaching design of high school mathematics can be effectively enhanced.

2.6 Teachers of the teaching method should further strengthen the guidance of classroom teaching design in the practice stage

In the practice of normal college students, teachers of the teaching method should participate in the lessons in the practice school, and organize all personnel (instruction teachers and practice students) to evaluate the lesson, and all personnel should elaborately analyze the whole teaching structure and the advantages and disadvantages of the lesson, and put forward improvement opinions for better designing the teaching of next lesson. In such process, each normal college students can be improved, and largely enhance their classroom teaching design ability and teaching skills.

\section{Main innovation points}

(1) The study and practice of the cultivation of the normal college student mathematics classroom teaching design ability accords with the standard requirement of new lesson of the Education Ministry, and it is the concrete application of modern education theory and modern learning theory, and the training mode has the character of innovation and strong operation character.

(2) Realize the combination of theory and practice, the combination of the in-class and out-class, and the combination 
of college and high school.

(3) Explain and demonstrate various parts of mathematics classroom teaching design, and organize normal college students to attempt to design various parts.

(4) Emphasize the demonstration function of the teaching method teacher, and pay attention to the discussion of students, and the communication and mutual evaluation among teachers and students.

(5) Implement students' practical training in the practice teaching and small classroom.

\section{Practice and effects}

(1) Normal college students of three consecutive terms (2005, 2006, and 2007) of the mathematics department in the Mianyang Normal University respectively participated in the experiment, and they had high passions and universal welcomes, and they highly evaluated the teaching reform experiment. And the practice result shows that the method and strategy in the experiment is effective and feasible.

(2) Whether in the practice report game in the practice schools, or in the classroom teaching game of excellent students in the Mianyang Normal University, the students in the department all obtained significant achievements. From 2005 to 2007, the education practice of the mathematics department all obtained the first prize of the university, and in the game of practice report lesson of 2006 and 2007 participated by students of five colleges in the Mianyang Nanshan High School (National Focus High School), the students of the mathematics department all obtained the first winner and the second winner at the same time (various specialties of various colleges only selected two players to participate in the game), and obtained the first winner and the second winner of the group of the science department in the classroom teaching game of excellent students in the school (various specialties only selected two players to participate in the game).

(4) There were five articles about relative research to respectively publish in the Theory and Practice of Education, Journal of Teaching and Management, Teacher Education Research and Journal of Mianyang Normal University.

(5) In the questionnaire investigation of 213 students in the experiment, $91.5 \%$ students though that it was very necessary to specially explain and train the mathematics classroom teaching design in the lesson of "subject teaching method", and it was propitious to normal college students to competent for the teaching works of the high school mathematics. $88.7 \%$ students thought that the cultivation of the classroom teaching design ability was very important to drive the classroom of high school mathematics. $94.8 \%$ students thought that in the teaching process of the lesson of "subject teaching method", it was very effective to emphasize the combination of theory and practice, and highly emphasize the cultivation of the teaching design ability. $96.7 \%$ students thought that it was very helpful to add the requirement of new lesson standards, new teaching concept, and new teaching mode in the classroom teaching design, which can help them to be welcomed by students of high school in the practice process.

\section{References}

Xu, Binyan. (2003). Teaching Course and Teaching Theory. Hangzhou: Zhejiang Education Press.

Zhang, Dianzhou \& Song, Naiqing. (2005). Introduction of Mathematics Education. Beijing: Higher Education Press.

Zhong, Qiquan, Cui, Yunhuo \& Zhang, Hua. (2001). Explanation of Reform Program of Elementary Education Courses. Shanghai: East China Normal University Press.

Zhou, Xiaoshan \& Yan, Xianyuan. (2002). Teaching Design Ideas and Teaching Mode of New Course. Chengdu: Sichuan University Press. 